\title{
Estimation of total nitrogen content in sugar beet leaves based on chlorophyll fluorescence parameters
}

\author{
C. FEI ${ }^{*, * *}$, H. FAN ${ }^{* *}$, X.X. FAN ${ }^{*,+}$, and G. XU ${ }^{*,+}$ \\ Jiangsu Academy of Agricultural Sciences, 210014 Nanjing, China* \\ Agricultural College, Shihezi University, 832003 Shihezi, China**
}

\begin{abstract}
Two sugar beet cultivars, Beta 356 and KWS9147, were grown in field trials at four different nitrogen contents $(0,75$, 150 , and $225 \mathrm{~kg} \mathrm{ha}^{-1}$ ), and each fertilizer treatment was divided into four applications (100\% prior to seeding; $70 \%$ prior to seeding and $30 \%$ at canopy development; $50 \%$ prior to seeding and $50 \%$ at canopy development; $30 \%$ prior to seeding and $70 \%$ at canopy development) in two consecutive growing seasons. Leaf chlorophyll fluorescence (ChlF) parameters and leaf nitrogen content were measured simultaneously at different growth stages, establishing an evaluation model of leaf nitrogen nutrition. The results showed that the correlation between ChlF parameters and leaf nitrogen content reached $0.7099^{* *}$ (canopy development), $0.8266^{* *}$ (storage root development) and $0.8607^{* *}$ (sugar accumulation stage). We conclude that the ChlF parameters can provide a decision-making method for $\mathrm{N}$ diagnosis and regulation in field production.
\end{abstract}

Additional key words: electron transport rate; maximum electron transfer efficiency; monitoring; nitrogen nutrition index.

Nitrogen $(\mathrm{N})$ is involved in the synthesis of amino acids, proteins, chlorophyll (Chl), and other substances in plants; it is one of the essential nutrients for growth, yield, and quality in crop (Choi et al. 2016, Jay et al. 2017). Yield and quality all increased with increasing $\mathrm{N}$ (within limits) application levels in cotton, maize, and so on. Excessive nitrogen fertilization may cause plant lodging, undesirable delayed senescence at later stages of growth, an increase in the incidence of pests and diseases, deterioration of crop yield and quality, and damage to the environment (Yang et al. 2012, Cordero et al. 2019). Timely diagnosis and timely quantitative fertilization are of great significance for crop growth. The traditional nitrogen management needs destructive sampling, which not only takes time and effort, but also delays the fertilization period. Fast, nondestructive, accurate monitoring and diagnosis of crop nitrogen nutritional status become more and more important and will help to determine the best management strategy and dynamic regulation of nitrogen use in crop.

Recently, the use of nondestructive plant phenotype technology has attracted much attention in crop nitrogen nutrition diagnosis and recommendation of nitrogen application. Recently, a Greenseeker (N Tech, USA) meter has been applied to chrysanthemum, cotton, grass, and other crops to evaluate crop nitrogen status (Jia et al. 2014, Bu et al. 2016, Colaco et al. 2018, Bracke et al. 2019). SPAD instrument (Konica Minolta, Japan) has been successfully applied to corn, Macadamia, potato, and other crops by measuring the $\mathrm{Chl}$ content of plant leaves to reflect the nitrogen nutrition of crops (Edalat et al. 2019, Galanti et al. 2019, Li et al. 2019). The digital imaging technology reflects the nitrogen nutrition status of crops, which is also related to wheat, coffee, and other crops (Elsayed et al. 2018, Putra and Soni 2018). Hyperspectral remote sensing technology has been shown to be a promising tool to rapidly monitor crop growth status, it has been used for nitrogen nutrition monitoring of soybean, rice, and other crops (Bi et al. 2018, Chlingaryan et al. 2018, Zhou et al. 2018). SPAD monitoring of plant nitrogen nutrition is easily affected by crop varieties and growth period. Digital imaging technology, GreenSeeker technology, and hyperspectral remote sensing technology are three technologies that have the drawback of providing a mixed measurement of signal originating from both the plants and the soil (Feng et al. 2015).

As an active remote sensing technology, chlorophyll fluorescence (ChlF) has a major advantage that fluorescence signals originate only from the plants. ChlF detection has been successfully used to monitor the health and growth of plants. Presently, there have been few reports on ChlF

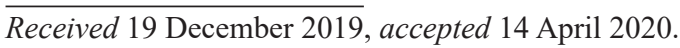

${ }^{+}$Corresponding author; e-mail: fxx600@163.com (X.X. Fan), xugang90@163.com (G. Xu)

Abbreviations: ChlF - chlorophyll fluorescence; $\mathrm{ETR}_{\max }$ - maximum electron transport rate; $\mathrm{F}_{\mathrm{m}}{ }^{\prime}$ - maximum fluorescence under light; $\mathrm{F}_{\mathrm{s}}$ - fluorescence in stable state; $\mathrm{F}_{\mathrm{v}} / \mathrm{F}_{\mathrm{m}}$ - maximum efficiency of PSII photochemistry under dark adaptation; $\mathrm{F}_{\mathrm{v}} / \mathrm{F}_{0}-$ potential activity of PSII; LNC - leaf nitrogen content; $\mathrm{q}_{\mathrm{N}}$ - nonphotochemical quenching.

Acknowledgements: This research was partially supported by the Safety Application Technology Optimization and Integration of Vegetable Production (2018YFD0800401). Thanks are due to Jiangsu Key Laboratory for Horticultural Crop Genetic Improvement. 
and the quantitative relationship with plant $\mathrm{N}$ status. The primary aim of this work was to evaluate the suitability of ChlF to accurately determine the plant $\mathrm{N}$ status in crops (sugar beet) using a hand-held device under field conditions. The anticipated results can provide technical support and a theoretical basis for diagnosing $\mathrm{N}$ nutrition and for recommending fertilization of the crop using the ChlF technique.

This experiment was conducted at the experiment station of Agricultural College, Shihezi University, China $\left(44^{\circ} 20^{\prime} \mathrm{N}, 88^{\circ} 30^{\prime} \mathrm{E}\right)$ in $2017-2018$ growing seasons. Sugar beet seeds (Beta356, Beta Seed Company, USA) were sown on 18 April, 2017 and 21 April, 2018 with a row spacing of $20 \mathrm{~cm}$ and a plant spacing of $50 \mathrm{~cm}$. Sugar beet seeds (KWS9147, KWS Seed Company, Germany) were sown on 21 April, 2018 with a row spacing of $20 \mathrm{~cm}$ and a plant spacing of $50 \mathrm{~cm}$. It was used to verify the reliability of the model. There were four $\mathrm{N}\left[\mathrm{CO}\left(\mathrm{NH}_{2}\right)_{2}\right](46 \% \mathrm{~N})$ treatments $\left(0,75,150\right.$, and $225 \mathrm{~kg}(\mathrm{~N}) \mathrm{ha}^{-1}$, as N0, N75, N150, and $\mathrm{N} 225$ ), and each fertilizer treatment was divided into four applications $(100 \%$ prior to seeding as $\mathrm{R} 1 ; 70 \%$ prior to seeding and $30 \%$ at canopy development as R2; $50 \%$ prior to seeding and 50\% at canopy development as R3; $30 \%$ prior to seeding and $70 \%$ at canopy development as R4). Irrigation $\left(7,500 \mathrm{~m}^{3} \mathrm{ha}^{-1}\right)$ was applied during the entire growth, with one drip irrigation tape laid between two rows of sugar beets. $\mathrm{P}$ and $\mathrm{K}$ fertilizers $\left(\mathrm{P}_{2} \mathrm{O}_{5}: 345 \mathrm{~kg} \mathrm{ha}^{-1}\right.$; $\mathrm{K}_{2} \mathrm{O}: 210 \mathrm{~kg} \mathrm{ha}^{-1}$ ) were applied once as base fertilizers.

After all $\mathrm{N}$ fertilizer was applied, functional leaves [at the canopy development stage (the $10^{\text {th }}$ leaf measured $50 \mathrm{~d}$ after emergence), at the storage root development stage (the $15^{\text {th }}$ leaf measured $75 \mathrm{~d}$ after emergence), and at the sugar accumulation stage (the $35^{\text {th }}$ leaf measured $91 \mathrm{~d}$ after emergence)] were selected to measure the fast light response curve by using the PAM-2500 chlorophyll fluorometer (Walz, Germany). First, leaves were darkadapted for 30 min using PAM-2500s (Walz, Germany) leaf clamp. The light intensity was set at $0,9,34,67,104$, 144, 201, 366, 622, 984; 1,163; and 1,666 $\mu$ mol(photon) $\mathrm{m}^{-2} \mathrm{~s}^{-1}$; and data were obtained after stabilization. The maximum electron transport rate $\left(\mathrm{ETR}_{\max }\right)$ was obtained by the instrument according to equation:

$$
\mathrm{ETR}=\mathrm{ETR}_{\max }\left(1-e^{-\mathrm{aPAR} / \mathrm{ETRmax}}\right) e^{-\beta \mathrm{PAR} / \mathrm{ETRmax}}
$$

where ETR is the electron transfer rate $\left[\mu \mathrm{mol}\left(\mathrm{e}^{-}\right) \mathrm{m}^{-2} \mathrm{~s}^{-1}\right]$; $\mathrm{ETR}_{\max }$ is maximum electron transfer efficiency $\left[\mu \mathrm{mol}\left(\mathrm{e}^{-}\right)\right.$ $\left.\mathrm{m}^{-2} \mathrm{~s}^{-1}\right]$; PAR is the photosynthetic active radiation [ $\mu$ mol(photon) $\left.\mathrm{m}^{-2} \mathrm{~s}^{-1}\right] ; \alpha$ is the initial slope of the curve (dimensionless); $\beta$ is photoinhibition parameter (dimensionless). Leaf nitrogen concentration (LNC [\%]) is the ratio between the total nitrogen accumulation in the leaves and the corresponding total dry mass at each period. All sample components were placed in a forced-air oven, killed for $30 \mathrm{~min}$ at $105^{\circ} \mathrm{C}$, and dried to a constant mass at $80^{\circ} \mathrm{C}$. The samples were ground, and the Kjeldahl method was used to determine the leaf nitrogen content (Bao 2000):
$\mathrm{N}=(\mathrm{V} \times 0.05 \times 14 \times 100) /(1,000 \times \mathrm{M})$

where $\mathrm{N}$ is the leaf nitrogen content $[\%] ; \mathrm{V}$ is the volume of $\mathrm{HCl}$ consumed [ml]; $\mathrm{M}$ is the mass of the sample [g].

The plant nitrogen nutrition index (NNI) was calculated according to Ata-Ul-Karim et al. (2014):

$\mathrm{NNI}=\mathrm{N}_{\mathrm{a}} / \mathrm{N}_{\text {opt }}$

where $\mathrm{N}_{\mathrm{a}}$ is the measured value of the nitrogen concentration [\%] in the leaf; $\mathrm{N}_{\mathrm{opt}}$ is the optimum nitrogen concentration obtained by the sugar yield nitrogen response model [\%] across the no- $\mathrm{N}$ treatment and the excessive- $\mathrm{N}$ treatment.

Statistical analyses were conducted with experimental data of three years using SPSS 12.0 software (SPSS Inc., Chicago, USA). Correlation analyses were conducted between ChlF parameters and leaf and plant $\mathrm{N}$ concentrations to determine the relationship between ChlF parameters and nitrogen concentration in leaves and plants. Plotting was completed with software Origin 8.5 (OriginLab, USA).

Regression analysis showed that at the canopy development, storage root development, and sugar accumulation stage, the relationships between ETR $_{\max }$ and leaf $\mathrm{N}$ concentration (LNC) had a unified regression equation. The relationship of $\mathrm{LNC}$ and $\mathrm{ETR}_{\max }$ exhibited a greater difference between canopy development, storage root development, and sugar accumulation stage, so the regression equations were established separately based on growth stages (Fig. $1 A-C$ ). At the canopy development, storage root development, and sugar accumulation stage, the differences in $\mathrm{ETR}_{\max }$ can reflect changes in LNC. There was a significant positive correlation between ETR $_{\max }$ and LNC in three growth periods, and the coefficient of determination $\left(R^{2}\right)$ was $0.7099(P<0.001), 0.8266$ $(P<0.001)$, and $0.8607 \quad(P<0.001)$, respectively. There was a significant positive correlation between measured value and analog value in three growth periods, and the correlation coefficient (r) was $0.906^{* *}(P<0.001), 0.946^{* *}$ $(P<0.001)$, and $0.930^{* *}(P<0.001)$, respectively (Fig. $\left.1 D-F\right)$. The best fit equation for LNC at different growth stages $v s$. sugar yield was parabolic, and the determination coefficient of $R^{2}>0.8086$ (Fig. 2). It can be seen from the curve that when the LNC exceeds a certain value in different growth periods, the sugar production decreases. According to the equation, we obtained the optimal LNC of three growth periods, which were $4.44,3.32$, and $4.01 \%$.

Nitrogen $(\mathrm{N})$ is a critical element for plant growth and productivity that influences photosynthesis and Chl fluorescence and LNC is a major biochemical parameter for estimating photosynthetic efficiency and crop yields (Yang et al. 2019). Previous studies have found that the yield and quality of crops decrease when the amount of nitrogen fertilizer exceeds a certain amount (Draycott and Christenson 2003, Bagherzadeh et al. 2014, Fei et al. 2019). So nondestructive and timely monitoring of crop structural and biochemical traits is of major importance to assess the physiological and phenological status of the 

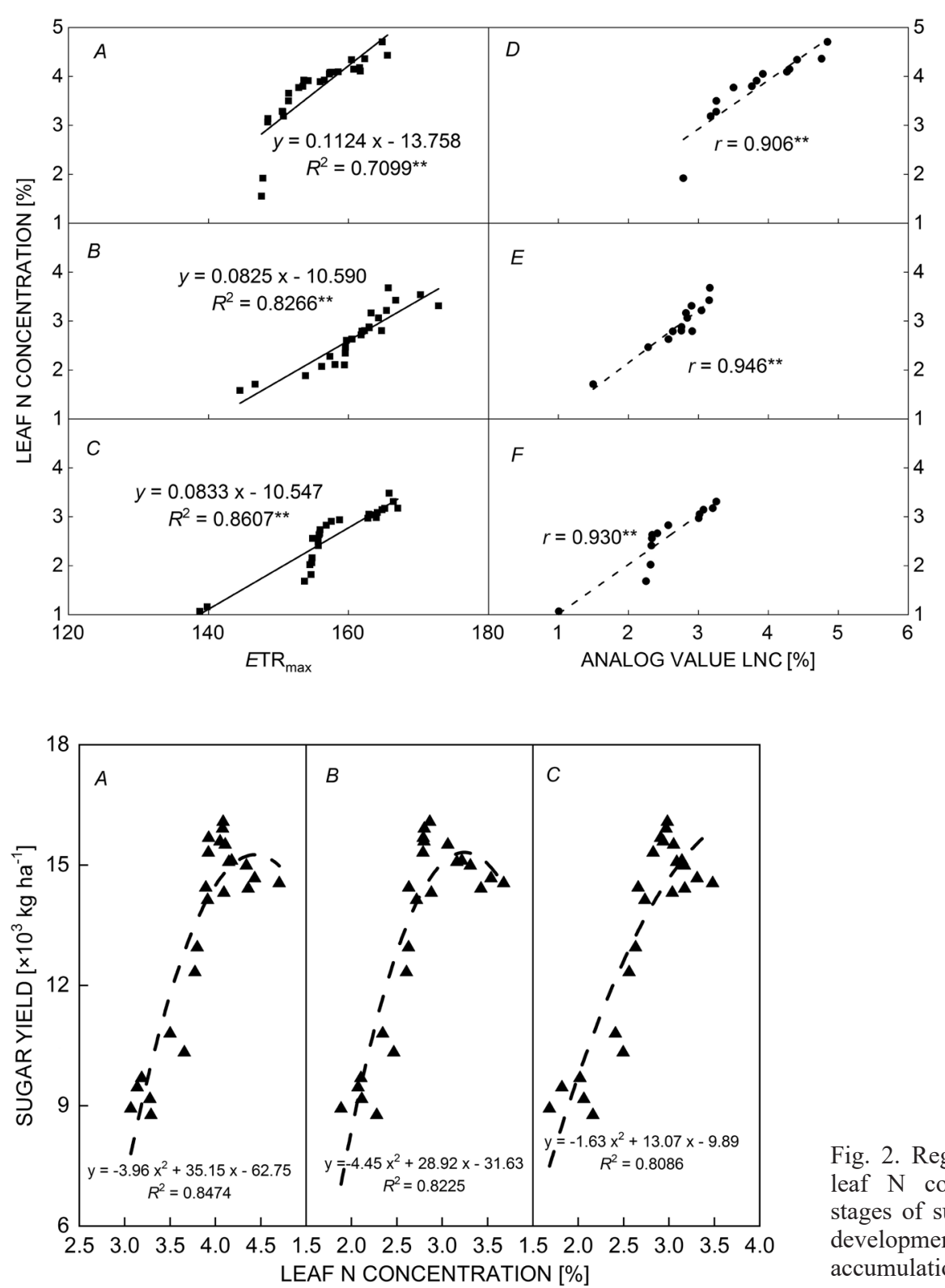

Fig. 1. Linear relationship between leaf nitrogen content (LNC) and maximum electron transport rate $\left(\mathrm{ETR}_{\max }\right)$ in sugar beet and 1:1 linear regression between simulated value and measured value. $(A, D)$ Canopy development; $(B, E)$ storage root development; $(C, F)$ sugar accumulation stage.
Fig. 2. Regression curves between sugar yield and leaf $\mathrm{N}$ concentration at different developmental stages of sugar beet in 2017 and 2018. (A) Canopy development; $(B)$ storage root development; $(C)$ sugar accumulation stage. plants and to further understand their functioning over time (Jay et al. 2019). The traditional methods of crop nitrogen diagnosis mainly include soil mineral nitrogen, plant total nitrogen, nitrate, and diphenylamine. Due to the difference of heredity and stage and the time needed, the application of these detection methods is restricted by some factors, such as poor adaptability, long processing time (Feng et al. 2015). Wang et al. (2020) pointed out that although hyperspectral and digital cameras were successfully applied to some crops, the results were very vulnerable to environmental factors. Some other studies have found that blue light-induced chloroplast movement in the leaves affects the accuracy of SPAD value (Nauš et al. 2010). Meanwhile, SPAD instrument may also cause irreversible damage to leaves. Chl fluorescence technology is an important noninvasive technology, which is used to evaluate and quantify the damage of photosynthetic apparatus, especially the PSII activity under environmental stress (Baker and Rosenqvist 2004). This method can avoid the influence of chloroplast movement by dark adaptation of the measurement area. Low-N stress significantly decreased $\mathrm{Chl}$ content and rapid light-response curves of $\mathrm{F}_{\mathrm{m}}{ }^{\prime}, \mathrm{F}_{\mathrm{s}}, \mathrm{q}_{\mathrm{N}}, \mathrm{F}_{\mathrm{v}} / \mathrm{F}_{\mathrm{m}}, \mathrm{F}_{\mathrm{v}} / \mathrm{F}_{0}$, and actual photochemical efficiency of PSII of leaves in maize (Wu et al. 2019). $\mathrm{N}$ fertilizer application significantly increased electron donor and acceptor performance of the PSII reaction center in winter wheat (Yang et al. 2018). Our results showed that LNC in sugar beet and the corresponding ChlF parameters varied significantly at different $\mathrm{N}$ levels, providing a rich source of information and a theoretical basis for estimating plant nitrogen status using the ChlF technique. There was a significant correlation between LNC and $\mathrm{ETR}_{\max }$. The overall accuracy of the simulation equation at leaf was high $\left(R^{2}>0.7\right)$, indicating that estimating a diagnosis standard 
for plant $\mathrm{N}$ status by $\mathrm{ETR}_{\max }$ measurement of a single leaf was reliable (Fig. $1 A-C$ ). Some studies have proposed that if the NNI $=1$, the nitrogen nutrition is appropriate. If the NNI $>1$, the nitrogen nutrition is excessive; if the $\mathrm{NNI}<1$, the nitrogen nutrition is insufficient (Ma et al. 2018). Calculating the NNI according to Eq. 3, we can make corresponding nitrogen management measures. Our study confirmed that chlorophyll fluorescence parameters can be used to monitor nitrogen nutrition of crops (sugar beet). This model can significantly facilitate the estimation of in-season crop (sugar beet) $\mathrm{N}$ requirement and provide strong technical support for the precision management of $\mathrm{N}$ fertilization.

\section{References}

Ata-Ul-Karim S.T., Zhu Y., Yao X., Cao W.: Determination of critical nitrogen dilution curve based on leaf area index in rice. - Field Crop. Res. 167: 76-85, 2014.

Bagherzadeh A., Kalat S.M.N., Hajian J.: Effects of residual wheat straw and nitrogen fertilizer on yield and quality of sugar beet in a semi-arid region. - Sugar Tech. 16: 189-194, 2014.

Baker N.R., Rosenqvist E.: Applications of chlorophyll fluorescence can improve crop production strategies: an examination of future possibilities. -J. Exp. Bot. 55: 1607-1621, 2004.

Bao S-D.: Soil and Agricultural Chemistry Analysis. Pp. 42-44. China Agriculture Press, Beijing 2000.

Bi Y.L., Kong W.P., Huang W.J.: Hyperspectral diagnosis of nitrogen status in arbuscular mycorrhizal inoculated soybean leaves under three drought conditions. - Int. J. Agr. Biol. Eng. 11: 126-131, 2018.

Bracke J., Eisen A., Adriaenssens S.: Utility of proximal plant sensors to support nitrogen fertilization in Chrysanthemum.Sci. Hortic.-Amsterdam 256:108544, 2019.

Bu H.G., Sharma L.K., Denton A., Franzen D.W.: Sugar beet yield and quality prediction at multiple harvest dates using active-optical sensors. - Agron. J. 108: 273-284, 2016.

Chlingaryan A., Sukkarieh S., Whelan B.: Machine learning approaches for crop yield prediction and nitrogen status estimation in precision agriculture: A review. - Comput. Electron. Agr. 151: 61-69, 2018.

Choi S.T., Kim S.C., Ahn G.H. et al.: Effects of different leaf-fruit ratios on uptake and partitioning of $\mathrm{N}$ and $\mathrm{K}$ in 'Uenishiwase' persimmon trees. - Sci. Hortic.-Amsterdam 212: 69-73, 2016.

Colaco A.F., Bramley R.G.V.: Do crop sensors promote improved nitrogen management in grain crops? - Field Crop. Res. 218: 126-140, 2018.

Cordero E., Longchamps L., Khosla R., Sacco D.: Spatial management strategies for nitrogen in maize production based on soil and crop data. - Sci. Total Environ. 697: 133854, 2019.

Draycott A.P, Christenson D.R.: Nutrients for Sugar Beet Production: Soil-Plant Relationships. Pp. 272. CABI Publishing, Wallingford 2003.

Edalat M., Naderi R., Egan T.P.: Corn nitrogen management using NDVI and SPAD sensor-based data under conventional vs. reduced tillage systems. - J. Plant Nutr. 42: 2310-2322, 2019.

Elsayed S., Barmeier G., Schmidhalter U.: Passive reflectance sensing and digital image analysis allows for assessing the biomass and nitrogen status of wheat in early and late tillering stages. - Front. Plant Sci. 9: 1478, 2018.

Fei C., Su J.X., Li Y.Y. et al.: Light-response characteristics of photosynthesis of drip-irrigated sugar beet under different nitrogen fertilizer managements. - Photosynthetica 57: 804$811,2019$.

Feng W., He L., Zhang H.Y.: Assessment of plant nitrogen status using chlorophyll fluorescence parameters of the upper leaves in winter wheat. - Eur. J. Agron. 64: 78-87, 2015.

Galanti R., Cho A., Ahmad A., Mollinedo J.: Use of a chlorophyll meter for nondestructive and rapid estimation of leaf tissue nitrogen in macadamia. - HortTechnology 29: 308-313, 2019.

Jay S., Baret F., Dutartre D. et al.: Exploiting the centimeter resolution of UAV multispectral imagery to improve remotesensing estimates of canopy structure and biochemistry in sugar beet crops. - Remote Sens. Environ. 231: 110898, 2019.

Jay S., Maupas F., Bendoula R., Gorretta N.: Retrieving LAI, chlorophyll and nitrogen contents in sugar beet crops from multi-angular optical remote sensing: Comparison of vegetation indices and PROSAIL inversion for field phenotyping. - Field Crop. Res. 210: 33-46, 2017.

Jia B., He H.B., Ma F.Y.: Use of a digital camera to monitor the growth and nitrogen status of cotton. - Sci. World J. 2014: 602647, 2014.

Li R., Chen J.H., Qin Y.L.: Possibility of using a SPAD chlorophyll meter to establish a normalized threshold index of nitrogen status in different potato cultivars. - J. Plant Nutr. 42: 834-841, 2019.

Ma L.L., Lv X., Zhang Z. et al.: [Establishment of nitrogen nutrition diagnosis model for drip-irrigation cotton based on critical nitrogen concentration.] - Trans. CSAM. 49: 277-283, 2018. [In Chinese]

Nauš J., Prokopová J., Řebíček J., Špundová M.: SPAD chlorophyll meter reading can be pronouncedly affected by chloroplast movement. - Photosynth. Res. 105: 265-271, 2010.

Putra B.T.W., Soni P.: Enhanced broadband greenness in assessing chlorophyll $a$ and $b$, carotenoid, and nitrogen in robusta coffee plantations using a digital camera. - Precis. Agric. 19: 238-256, 2018.

Wang Y., Shi P.H., Ji R.T. et al.: Development of a model using the nitrogen nutrition index to estimate in-season rice nitrogen requirement. - Field Crop. Res. 245: 107664, 2020.

Wu Y.W., Li Q., Jin R. et al.: Effect of low-nitrogen stress on photosynthesis and chlorophyll fluorescence characteristics of maize cultivars with different low-nitrogen tolerances. J. Integr. Agr. 18: 1246-1256, 2019.

Yang D.Q., Dong W.H., Luo Y.L. et al.: Effects of nitrogen application and supplemental irrigation on canopy temperature and photosynthetic characteristics in winter wheat. - J. Agr. Sci. 156: 13-23, 2018.

Yang G.Z., Tang H.Y., Tong J.: Effect of fertilization frequency on cotton yield and biomass accumulation. - Field Crop. Res. 125: 161-166, 2012.

Yang J., Du L., Shi S. et al.: Potential of fluorescence index derived from the slope characteristics of laser-induced chlorophyll fluorescence spectrum for rice leaf nitrogen concentration estimation. - Appl. Sci. 9: 916, 2019.

Zhou K., Cheng T., Zhu Y. et al.: Assessing the impact of spatial resolution on the estimation of leaf nitrogen concentration over the full season of paddy rice using near-surface imaging spectroscopy data. - Front. Plant Sci. 9: 964, 2018.

(C) The authors. This is an open access article distributed under the terms of the Creative Commons BY-NC-ND Licence. 